\title{
Spatial correlograms and landscape metrics as indicators of land use changes
}

\author{
R. Aunap, E. Uuemaa, J. Roosaare \& Ü. Mander \\ Institute of Geography, University of Tartu, Estonia
}

\begin{abstract}
Land use changes over time can be analysed in several ways. We studied the spatial autocorrelation (Moran's I) of raster format land use maps from three different time periods $(1900,1940$, and 2000) in 13 study areas representing most of the landscape regions in Estonia. Human influence was taken into consideration in compiling a scale of the contrast between 10 land use groups. We introduce a simple characteristic based on spatial correlograms: a half-value distance lag, $\mathrm{h}_{\mathrm{I}=0.5}$ - a distance where Moran's I drops below 0.5. No significant change was detected in values of $\mathrm{h}_{\mathrm{I}=0.5}$ over time. In addition, we did not detect a difference between lowlands and heights. In analysis of landscape metrics Edge Density (ED), Patch Density (PD), Contrast Weighted Edge Density (CWED), Mean Patch Area Distribution (AREA_MN), and Percentage of Like Adjacencies (PLADJ) showed significant changes comparing the year 2000 with 1900 and 1940. However, the results showed no significant change in landscape metrics between 1900 and 1940. ED, PD and CWED had higher values in 2000 than in 1900 and 1940. Therefore landscape heterogeneity has increased in recent decades. ED, PD, CWED, AREA_MN and PLADJ metrics also indicated a significant difference between lowlands and heights. It appeared that heights have a more heterogeneous landscape structure than lowlands. Generally, the heterogeneity of Estonia's landscapes overall has changed within recent decades. Keywords: FRAGSTATS metrics, landscape pattern, landscape regions, land use change, Moran's I, spatial autocorrelation.
\end{abstract}

\section{Introduction}

Studies on land use changes is the basic area in landscape research $[1,2]$ being one of the key issues in global environmental change [3]. Both natural and socio- 
economic factors have been used in the analysis of land use changes $[4,5]$. In the majority of them, the main problem is to correctly characterize the spatial pattern using various landscape metrics $[6,7]$.

Widely used means to describe landscape texture metrics can be calculated with the help of FRAGSTATS [8]. It has been shown $[9,10]$ that these metrics are scale-dependent, and not all indexes demonstrate a regular behaviour in relation to scale changes.

Despite the great number of indexes, FRAGSTATS does not include measures of variography, e.g. different spatial structure functions such as correlograms and variograms, which are popular in geostatistics [11], and describe the dependence of variability on distance. In order to study landscape heterogeneity and spatial autocorrelation, correlograms are preferred to semivariograms, since - according to Legendre and Fortin [6] - they are standardized and make it possible to compare different landscapes. This method is used by Radeloff et al. [12] to study artificial landscapes with a regular pattern, in order to detect periodicity in their correlograms. The behaviour of a correlogram's wavelength and amplitude within a specific range of spatial orders can be used as an indicator of spatial pattern [13].

A classical estimator of spatial dependence is Moran's I, "associated with statistician P.A. Moran (1948)" and proposed as the spatial analogy of autocorrelation used in time series analysis [14]. Since the introduction of the autocorrelation index by Moran [15], spatial correlograms have been used for the spatial analysis of several natural and social phenomena. At present, various studies use Moran's I correlograms to avoid systematic mistakes due to spatial autocorrelation in spatial analyses $[6,16,17,18]$, or using the correlograms for ecological and landscape analyses at different spatial scales. Koenig [19] showed the importance of the Moran effect and spatial autocorrelation (environmental synchrony) for the analysis of patterns of animal populations at continental and global scale. Likewise, Diniz-Filho et al. [20] calculated the Moran's autocorrelation value when analysing avian populations at continental scale. Large-scale (100-1000 km) analysis of Moran's I correlograms was carried out for the investigation of vegetation pattern dynamics in the Great Lakes region during the Holocene [21], for the prediction of deforestations in Saskatchewan [22], for the analysis of human land transformations in South African avian diversity [23], for the identification of operational units for conservation in continuous populations [24], and for the analysis of alien plant invasion in Catalonia [25]. At the local and landscape scale (10-1000 m), Moran's I was used for analyses of the distribution pattern of several bird and mammal species [26], carabid beetles [27], Neotropical migrant songbirds [17], the impacts of logging in Amazonian forests [28], urban spatial features [29], the variability of soil properties in wetlands [30], and the spatial patterns of greenhouse gas emissions in tropical rainforests [31].

Surprisingly, we were able to find only two papers in which Moran's I statistic has been used in connection with changes in land use/cover [32] or vegetation cover [33]. Read and Lam [32] have found that Moran's I is effective 
at detecting changes in land cover types in Costa Rica's lowlands, whereas FRAGSTATS indexes were not sufficient in this sense.

The main objectives of this study were: (1) to analyse three map series (from approximately 1900, 1940, and 2000) of selected landscape areas in Estonia concerning their differences in spatial autocorrelation and FRAGSTATS indexes; (2) to find out whether the Moran's I characteristic and landscape indexes respond to the land cover changes.

\section{Material and methods}

\subsection{Study areas}

Thirteen study areas were selected on the basis of Estonian landscape regions so that they represent most Estonian landscape types (Fig. 1). The selection of study sites was based on Uuemaa et al [34].

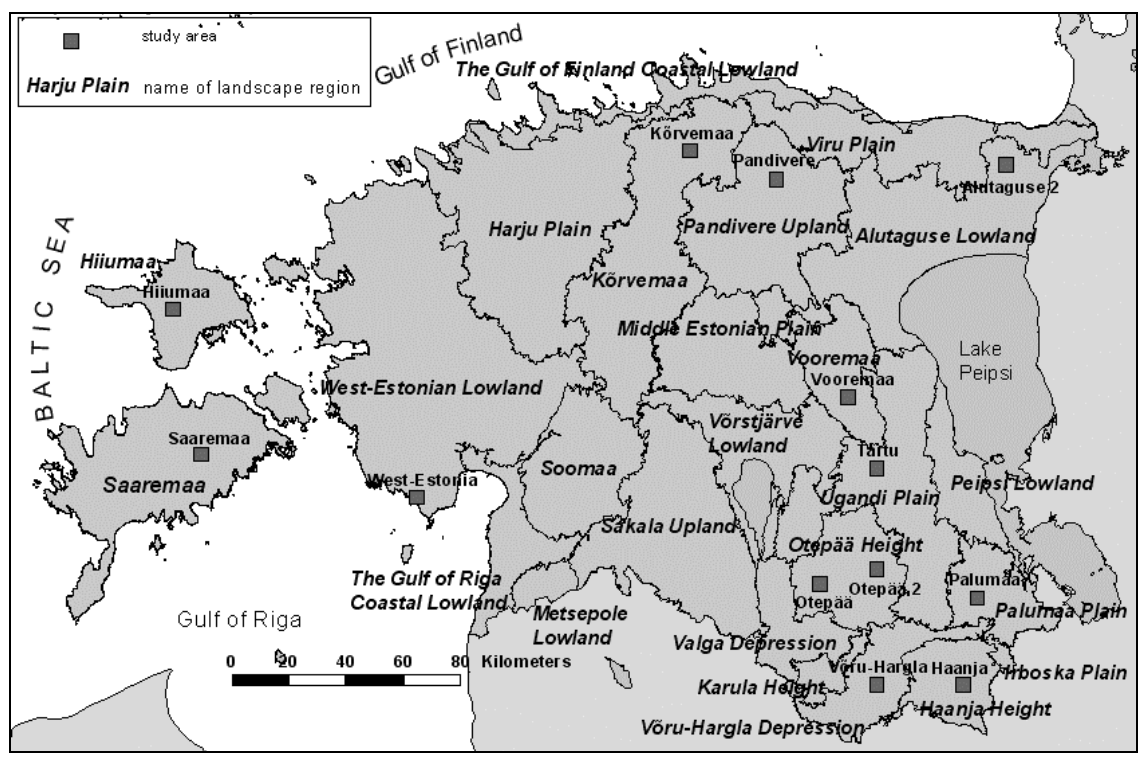

Figure 1: $\quad$ Study areas and landscape regions of Estonia.

Of 13 study areas, there were sites dominated by agricultural land use, forests, bogs or urban areas. Study areas were formed on the basis of Estonian Basic Map Sheets. Each study area was $5 * 5 \mathrm{~km}$.

\subsection{Land use data}

Land use data was derived from three maps from different time periods: 1:42,000 (from Russian topographic map sheets dating from 1886-1917; later referred to as "1900"), 1: 50,000 (topographic map sheets published by the Estonian 
Military Topo-Hydrographic Department, in 1935-1939; later referred to as "1940"), and 1:20,000 (Estonian Basic Map sheets from 1998-2004; generalised to $1: 50,000$ scale; later referred to as "2000") and converted into raster format using $10 \mathrm{~m}$ pixel size.

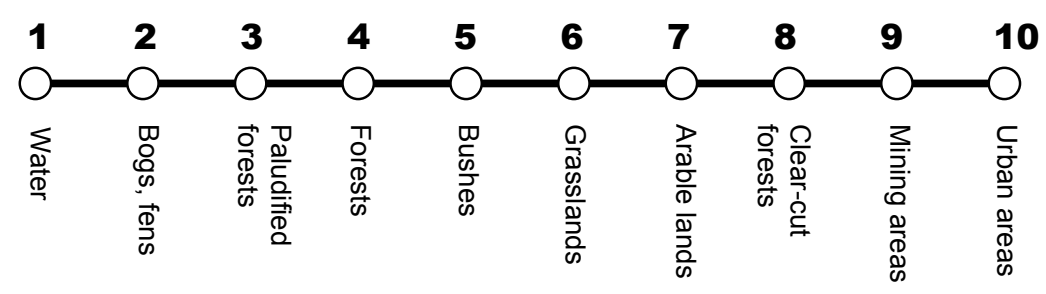

Figure 2: Scale of the contrast of main land use types.

For the generalisation of the 1:20,000 Estonian Basic Map sheets into the 1:50,000 scale, we used the MapInfo tools Polygon Area Thinning and Gap Removal. The minimum recognisable area was set to 0.4 ha.

The maps of the test sites were scanned (except for the Estonian Basic Map, which is already in digital form), digitised, and rasterized. Ten land use types distinguished from all map series were reclassified so that new type numbers could be used as contrast indexes (Fig. 2). In the case of land use types $M_{i}$ and $\mathrm{M}_{\mathrm{j}}$, their difference $(|\mathrm{i}-\mathrm{j}|)$ shows the contrast between these types.

\subsection{Moran's I}

In our analysis we applied the Idrisi Kilimanjaro software [35]. A module named AUTOCORR calculates the first-lag autocorrelation coefficient of an image. The following equation, which is similar to the usage in other software, is applied:

$$
I=n \cdot \frac{\sum_{i=1}^{n} \sum_{j=1}^{n} w_{i j}\left(y_{i}-\mu\right)\left(y_{j}-\mu\right)}{\left(\sum_{i \neq j} \sum w_{i j}\right)\left(\sum_{i=1}^{n}\left(y_{i}-\mu\right)^{2}\right)}
$$

where $n-\quad$ number of values to be taken into account (in the case of a raster image, pixels); $w$ - spatial weights: 1 in the directions up/down/left/right, 0.70711 (square root of 2) as a weight for the diagonal neighbouring pixels; $y_{i j}$ value of pixel $i$ resp. $j ; \mu-$ mean of values $y$ [36].

In addition to Moran's I, Idrisi also calculates several statistics including tests of significance under two null hypothesis assumptions.

For raster images, the autocorrelation has been calculated with all appropriate pixels using so-called King's case analysis [35]. 
Using auxiliary images (the CONTRACT module with so-called pixel thinning), we computed the $1^{\text {st }}, 2^{\text {nd }}, 3^{\text {rd }}$ etc. lags of Moran's I value. Accordingly, we found all necessary $I_{h}$, changing $h$ as a multiple of pixel resolution. In our investigation, the size of the pixel side was $10 \mathrm{~m}$, and for the test sites we calculated series of $I_{h}, h=10,20,30, \ldots, 100,120, \ldots, 200,300,400,500$ and $1000 \mathrm{~m}$. We used the results to construct the graphs of $I(h)$, called correlograms, which ideally are monotonically decreasing curves. Since $n$ is very large (tens and hundreds of thousands), all $I(h)$, except for some $I(1000)$, are statistically significant.

We investigated the correlograms of the test areas based on 3 map series from different periods, and found these to be quite regular. In order to compare Moran's I correlograms from different test areas and different map series and also with other landscape metrics derived from FRAGSTATS, we introduced a simple characteristic of half-value distances: $\mathrm{h}_{\mathrm{I}=0.5}$ - the distance lag where Moran's I drops below 0.5 [34].

\subsection{Landscape metrics}

Using FRAGSTATS 3.3, landscape metrics were calculated for all study sites. We calculated the following landscape metrics: 1) Edge Density (ED); Patch Density (PD); Mean Patch Area Distribution (AREA_MN); Mean Shape Index (SHAPE_MN), Contrast Weighted Edge Density (CWED); Percentage of Like Adjacencies (PLADJ); Contagion (CONTAG) and Shannon's Diversity Index (SHDI). For details and metrics formulae see McGarigal and Marks [8].

\subsection{Statistical analysis}

According to the Kolmogorov-Smirnov test for normality, all of the variables under consideration were normally distributed. The homogeneity of variances was verified using the Cochran $\mathrm{C}$ and Levene tests. In correlogram analysis, when comparing different groups we used a one-way ANOVA (Tukey's HSD test). In landscape metric analysis, most of the variables did not meet the analysis of variance assumptions (Levene and Cochran $\mathrm{C}$ tests). Therefore, the significance of differences was analysed using the non-parametric KruskalWallis test. For the statistical analysis of all data, the computer program STATISTICA 7.1 was used. The level of significance of $\alpha=0.05$ was accepted in all cases.

\section{Results and discussion}

\subsection{Moran's I correlograms}

We did not detect statistically significant land use changes during the years 1886-2004. The overall significance of the model was $>0.3$, and also Tukey's HSD test did not show significant differences between group means. Therefore we could say that landscapes overall have not changed significantly over the past 100 years in Estonia. However, Figure 3 shows that the mean of the $\mathrm{h}_{\mathrm{I}=0.5}$ 
decreased from 250 in 1900 to 160 in 2000 (Fig. 3). Also, the variation is smaller in 2000. Therefore we could say that human influence has made landscapes slightly more heterogeneous. We could even claim that land use in some areas did change dramatically. In Alutaguse paludified lowland, for example, the forests and bogs were turned into mining areas during the last 50 years (Fig. 4). However, the heterogeneity of the landscape has decreased (Fig. 5). In 2000 the spatial autocorrelation is highest, and in 1940 lowest. In the case of West Estonia it is vice versa (Fig. 5). In recent decades the spatial autocorrelation has decreased, i.e. human influence has increased the heterogeneity of landscape. In the case of all heights except Vooremaa, the spatial autocorrelation had decreased in recent decades. Landscapes were more heterogeneous in 2000 than they were a hundred years ago.
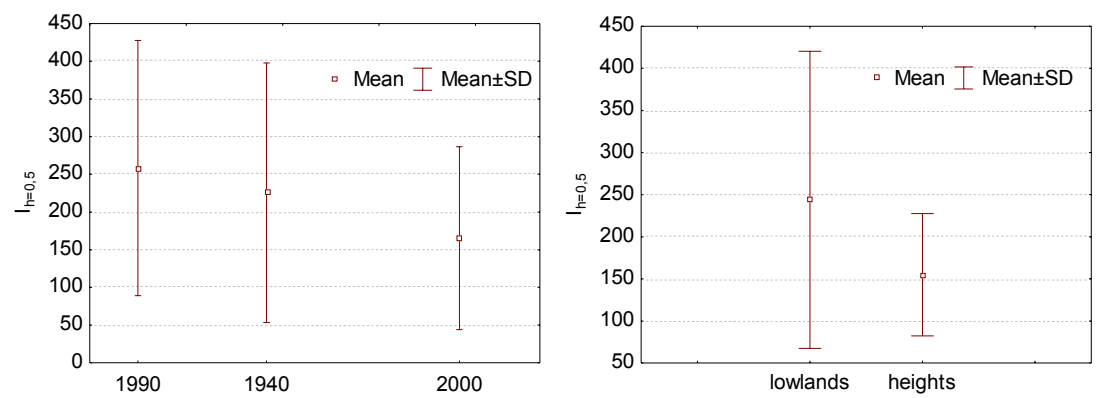

Figure 3: Average and standard deviation values of Moran's Ih50 of 3 map series (1900, 1940, 2000), and heights and lowlands over all 13 test sites.

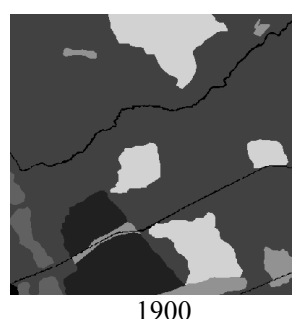

900

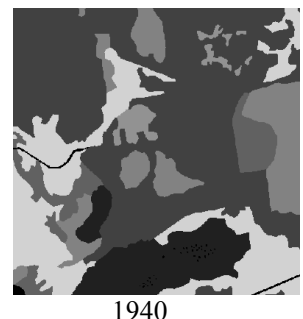

1940

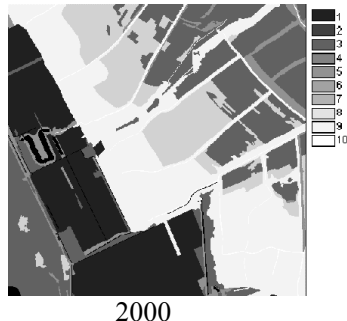

2000

Figure 4: Land use change in the test area of the Alutaguse 2 paludified lowlands. For numbers of land use types, see Table 1.

We also found that there is no significant difference between $I_{h 50}$ in heights and lowlands as could be expected based on the results obtained by Uuemaa et al. [34]. The Tukey HSD test did not show a statistically significant difference between heights and lowlands. Nevertheless, it can be seen from Figure 3 that the mean of the $\mathrm{I}_{\mathrm{h} 50}$ is 155 in the case of heights and 250 in the case of lowlands. The variation of $\mathrm{I}_{\mathrm{h} 50}$ is also smaller. This shows that the spatial autocorrelation of 
heights is lower than the autocorrelation of lowlands, i.e. lowlands are more spatially homogenous. This can also be seen from Fig. 5, where the decrease of correlograms is more abrupt in the case of heights (Vooremaa and Otepää) than in the case of lowlands (Alutaguse 2 and West-Estonia).
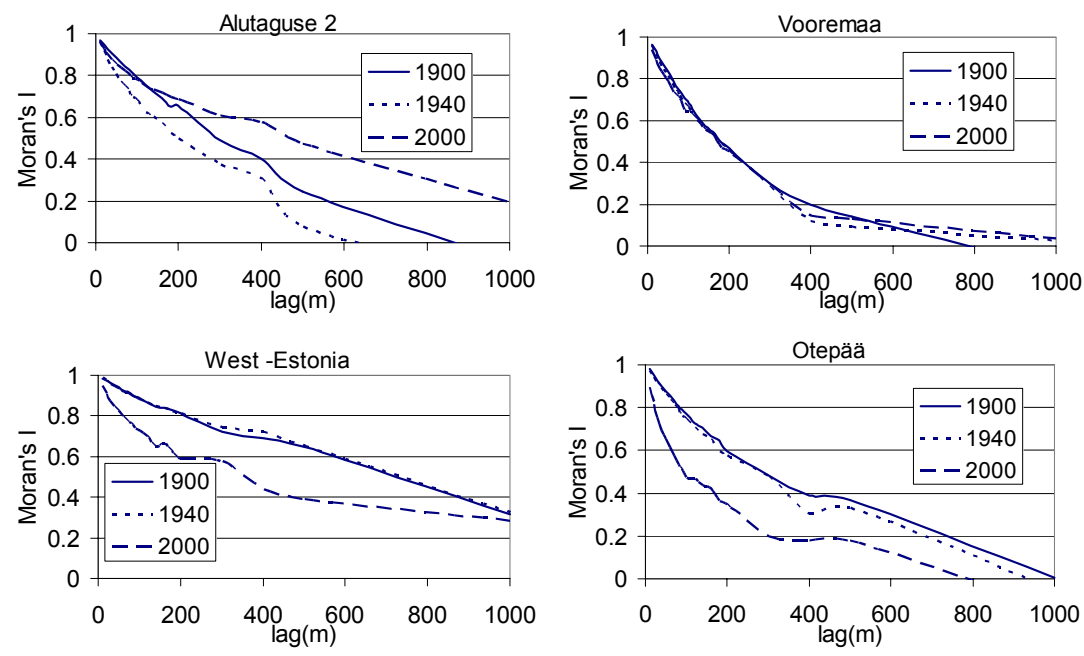

Figure 5: $\quad$ Spatial correlograms of 3 map series $(1900,1940,2000)$ from 4 test areas.

Interestingly, we found that near $180 \mathrm{~m}$ and $400 \mathrm{~m}$ of lag distance, a "jump" appeared on almost each correlogram (Fig. 5). This phenomenon is probably related to the periodicity of Moran's I correlograms, which was, however, only detected at larger scales [12].

\subsection{Landscape metrics}

Although no change in $\mathrm{I}_{\mathrm{h} 50}$ values appeared in the analysis of correlograms, statistically significant changes were detected in several values of landscape metrics.

The average values and standard deviations in the years 1900 and 1940 are very stable (Table 1). In 2000, remarkable changes can be detected in values of PD, ED, AREA_MN, CWED and PLADJ. These metrics also gave statistically significant changes in the Kruskal-Wallis test (Table 2). No change was detected between 1900 and 1940, which also confirms the results of Palang et al., [37]. ED, PD and CWED had increased in 2000 compared to earlier dates (Fig. 6). This shows that heterogeneity has increased in recent decades. AREA_MN and PLADJ had decreased in recent decades, which also indicates the increase in landscape heterogeneity.

We also tried to identify differences between heights and uplands. The results showed that PD, ED and CWED values are significantly lower in the lowlands (Table 2 and Fig. 6), i.e. the landscape structure is more homogenous than in the 
heights. Palang et al. [37] obtained similar results: in southern Estonia, where all the heights are located, test sites had higher heterogeneity. AREA_MN and PLADJ had lower values in heights (Table 2), i.e. landscape patches are smaller, and therefore the landscape has a more complex structure than in the lowlands.

Table 1: Average values and standard deviations of measured landscape metrics. *significant difference with $2000(\mathrm{p}<0,01)$.

\begin{tabular}{llll}
\hline & \multicolumn{1}{c}{1900} & \multicolumn{1}{c}{1940} & \multicolumn{1}{c}{2000} \\
\hline PD & \multicolumn{1}{c}{$2.66 \pm 1.78^{*}$} & $3.26 \pm 1.75^{*}$ & $15.03 \pm 7.15$ \\
ED & $46.467 \pm 20.73^{*}$ & $51.94 \pm 19.75^{*}$ & $100.83 \pm 28.85$ \\
AREA_MN & $56.97 \pm 42.56^{*}$ & $38.58 \pm 18.63^{*}$ & $8.20 \pm 3.81$ \\
SHAPE_MN & $1.88 \pm 0.28$ & $1.76 \pm 0.12$ & $1.81 \pm 0.24$ \\
CWED & $19.43 \pm 7.57 *$ & $22.47 \pm 7.65^{*}$ & $44.01 \pm 12.96$ \\
CONTAG & $63.384 \pm 7.86$ & $60.14 \pm 6.02$ & $61.82 \pm 6.44$ \\
PLADJ & $97.48 \pm 1.04^{*}$ & $97.20 \pm 0.99 *$ & $94.76 \pm 1.44$ \\
SHDI & $1.3 \pm 0.30$ & $1.39 \pm 0.22$ & $1.28 \pm 0.22$ \\
\hline
\end{tabular}

Table 2: Changes in landscape metrics agewise and difference between lowlands and heights. Estimated by Kruskal-Wallis test (significance levels $* * * p<0.001 ; * * p<0.01 ; * \mathrm{p}<0.05$ ).

\begin{tabular}{lll}
\hline & \multicolumn{1}{c}{ Agewise } & \multicolumn{1}{c}{ Lowlands and heights } \\
\hline PD & 1900 and $1940<2000^{* * *}$ & lowlands $<$ heights* \\
ED & 1900 and $1940<2000^{* *}$ & lowlands $<$ heights** \\
AREA_MN & 1900 and $1940>2000 * * *$ & lowlands $>$ heights* \\
SHAPE_MN & no difference & no difference \\
CWED & 1900 and $1940<2000 * *$ & lowlands $<$ heights* \\
CONTAG & no difference & no difference \\
PLADJ & 1900 and $1940>2000 * *$ & lowlands $>$ heights** \\
SHDI & no difference & no difference \\
\hline
\end{tabular}

Summarizing the results of this study, the heterogeneity of Estonian landscapes has changed over the last 50 years, according to landscape metrics analysis. However, the spatial autocorrelation of landscapes has not changed significantly, but it also showed decreasing trends in recent decades. The results of this analysis were not unequivocal, because in some study areas the heterogeneity had increased, and some study areas had become more homogeneous over time. Thus the overall change in Estonian landscapes is not so remarkable. 

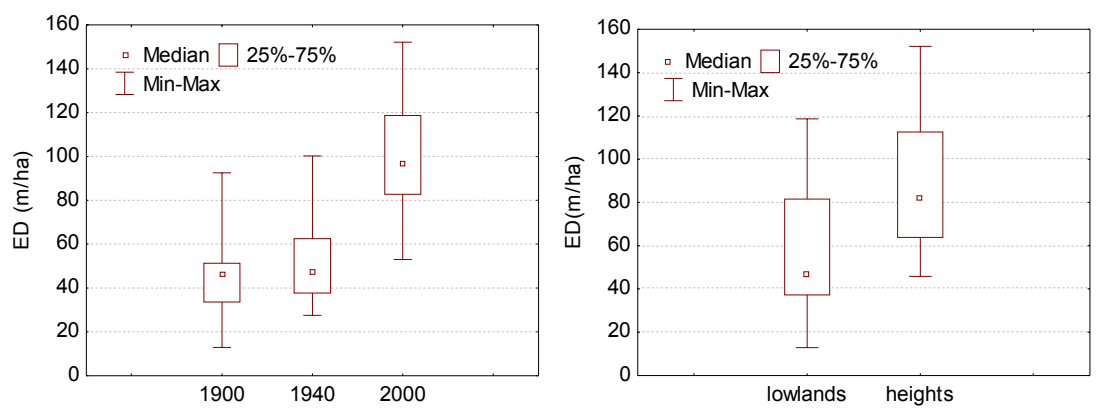

Figure 6: Median, quartiles, maximum and minimum values of ED of 3 map series (1900, 1940, 2000), and heights and lowlands over all 13 test sites.

\section{Conclusions}

The results of the study demonstrated that the average value of spatial autocorrelation in Estonian landscapes has not significantly changed over time. We were also unable to find a significant difference between spatial autocorrelation in heights and lowlands. We propose the distance (lag) of spatial correlograms at which the Moran's I value reaches $50 \%$ of the maximal value $\left(\mathrm{h}_{\mathrm{I}=0.5}\right)$ as a new landscape metric for the characterization of landscape pattern. Its benefit is its simple interpretability and the independence of the scale. Thus this characteristic can effectively be used as an indicator in landscape planning and management.

Although the analysis of correlograms did not show significant change over time, several landscape metrics indicated that landscapes are more heterogeneous in 2000 than they were in 1900 or 1940 . There was also a statistically significant difference between heights and lowlands, latter being more homogeneous.

\section{Acknowledgements}

This study was supported by Estonian Science Foundation grant No. 6083 and Target Funding Project No. 0182534s03 of the Ministry of Education and Science of Estonia. We acknowledge Sten Mander for his help in digitizing maps.

\section{References}

[1] Forman, R.T.T., Godron, M., Landscape Ecology, John Wiley and Sons, New York, 619 p., 1986.

[2] Zonneveld, I., Land Ecology, SPB Academic Publishing, Amsterdam, 199 pp., 1995.

[3] Alcamo, J., Leemans, R., Kreileman. E., Global Change Scenarios of the $21^{\text {st }}$ Century, Results from the IMAGE 2.1 Model, Elsevier Science Publishers, London, UK, 287 pp., 1998. 
[4] Wear, D.N., Bolstad, P., Land-use changes in southern Appalachian landscapes: Spatial analysis and forest evaluation, Ecosystems, 1(6), 575594, 1998.

[5] McDonald, R. I., Urban, D.L., Spatially varying rules of landscape change: lessons from a case study, Landscape Urban Plan. 74(1), 7-20, 2006.

[6] Legendre, P., Fortin, M.-J., Spatial pattern and ecological analysis, Vegetatio, 80(2):107-138, 1989.

[7] Gustafson, E.J., Quantifying landscape spatial pattern: What is the state of the art? Ecosystems 1(1), 143-156, 1998.

[8] McGarigal, K., Marks, B.J., FRAGSTATS: spatial pattern analysis program for quantifying landscape structure, USDA Forest Serv. Gen. Tech. Rep. PNW-351, 1995.

[9] Wu, J., Shen, W., Sun, W., Tueller, P. T., Empirical patterns of the effects of changing scale on landscape metrics, Landscape Ecol. 17(8), 761-782, 2002.

[10] Uuemaa, E., Roosaare, J., Mander, Ü., Scale dependence of landscape metrics and their indicatory value for nutrient and organic matter losses from catchments, Ecol. Indic. 5(4), 350-369, 2005.

[11] Cressie, N.A.C., Statistics for Spatial Data, Revised Edition. Wiley, New York, 1993.

[12] Radeloff, V.C., Miller, T.F., He, H.S., Mladenoff, D.J., Periodicity in spatial data and geostatistical models: autocorrelation between patches, Ecography 23(1), 81-91 2000.

[13] Chou, Y.H., Spatial pattern and spatial autocorrelation, Lect. Notes Comput. Sc. 988, 365-376, 1995.

[14] Taylor, P.J., Quantitative methods in geography, Houston Mifflin Company, Boston 1977.

[15] Moran, P.A., The interpretation of statistical maps, J. Royal Stat. Soc. B 10, 243-251 1948.

[16] Legendre, P., Spatial autocorrelation: Trouble or new paradigm? Ecology, 74(6): 1659-1673, 1993.

[17] Lichstein, J.W., Simons, T.R., Shriner, S.A., Franzreb, K.E., Spatial autocorrelation and autoregressive models in ecology, Ecol. Monogr. 72(3), 445-463, 2002.

[18] Overmars, K.P., de Koning, G.H.J., Veldkamp, A., Spatial autocorrelation in multi-scale land use models, Ecol. Model. 164(2-3), 257-270 2003.

[19] Koenig, W.D., Global patterns of environmental synchrony and the Moran effect, Ecography 25(3), 283-288, 2002.

[20] Diniz-Filho, J.A.F., Bini, L.M., Hawkins, B.A., Spatial autocorrelation and red herrings in geographical ecology, Global Ecol. Biogeogr. 12, 5364, 2003.

[21] Graumlich, L.J., Davis, M.B., Holocene variation in spatial scales of vegetation pattern in the upper Great Lakes, Ecology 74(3), 826-839, 1993. 
[22] Hobson, K.A., Bayne, E.M., van Wilgenburg, S.L., Large-scale conversion of forest to agrculture in the boreal plains of Saskatchewan, Conserv. Biol. 16(6), 1530-1541, 2002.

[23] Fairbanks, D.H.K., Kshatriya, M., van Jaarsveld, A.S., Underhill, L.G., Scales and consequences of human land transformation on South African avian diversity and structure, Anim. Conserv. 5, 61-73, 2002.

[24] Diniz, J.A.F., Telles, M.P.D., Spatial autocorrelation analysis and the identification of operational units for conservation in continuous populations, Conserv. Biol. 16(4), 924-935, 2002.

[25] Pino, J., Font, X., Carbo, J., Jove, M., Pallares, L., Large-scale correlates of alien plant invasion in Catalonia (NE of Spain), Biol. Conserv. 122(2), 339-350, 2005.

[26] Koenig, W.D., Knops, J.M.H., Testing for spatial autocorrelation in ecological studies, Ecography 21(4), 423-429, 1998.

[27] Judas, M., Dornieden, K., Strothmann, U., Distribution patterns of carabid beetle species at the landscape-level, J. Biogeogr. 29(4), 491-508, 2002.

[28] Read, J.M., Spatial analyses of logging impacts in Amazonia using remotely sensed data, Photogramm. Eng. Rem. S. 69(3), 275-282, 2003.

[29] Myint, S.W., Kam, N.S.-N., Tyler, J.M., Wavelets for urban spatial feature discrimination: Comparisons with fractal, spatial autocorrelation, and spatial co-occurrence approaches, Photogramm. Eng. Rem. S. 70(7), 803-812, 2004.

[30] Bruland, G.L., Richardson, C.J., Spatial variability of soil properties in created, restored, and paired natural wetlands, Soil Sci. Soc. Am. J. 69, 273-284, 2005.

[31] Ishizuka, S., Iswandi, A., Nakajima, Y., Yonemura, S., Sudo, S., Tsuruta, H., Muriyarso, D., Daniel Spatial patterns of greenhouse gas emission in a tropical rainforest in Indonesia, Nutr. Cycl. Agroecosys. 71(1), 55-62, 2005.

[32] Read, J.M., Lam, N.S.-N., Spatial methods for characterising land cover and detecting land-cover changes for the tropics, Int. J. Rem. S. 23(12), 2457-2474, 2002.

[33] Landis, A.G., Bailey, J.D., Reconstruction of age structure and spatial arrangement of piñon-juniper woodlands and savannas of Anderson Mesa, northern Arizona, Forest Ecol. Manag. 204(2-3), 221-236, 2005.

[34] Uuemaa, E., Roosaare, J., Kanal, A., Mander, Ü., Spatial correlograms of soil cover as an indicator of landscape heterogeneity, Ecol. Indic. Submitted, 200X.

[35] Eastman, R., IDRISI Kilimanjaro: Guide to GIS and Image Processing, Clark University, 2003. http://www.sbg.ac.at/geo/idrisi/wwwtutor/s tools7.htm [24.11.05], 1999.

[37] Palang, H., Mander, Ü., Luud, A., Landscape diversity changes in Estonia, Landscape Urban Plan. 41(3-4), 163-170, 1998. 